\title{
Tracking Nitrogen Sources, Transformation, and Transport at a Basin Scale with Complex Plain River Networks
}

\author{
Qitao $\mathrm{Yi}^{\ddagger}{ }^{\ddagger}{ }^{8}$ Qiuwen Chen, ${ }^{*}{ }^{\dagger, \ddagger}+$ Liuming $\mathrm{Hu}^{\dagger}{ }^{\dagger}$ and Wenqing $\mathrm{Shi}^{\dagger}$
}

${ }^{\dagger}$ Center for Eco-Environment Research, Nanjing Hydraulic Research Institute, Nanjing 210098, China

${ }^{\ddagger}$ Research Center for Eco-Environment Sciences, Chinese Academy of Sciences, Beijing 100085, China

${ }^{\S}$ School of Earth and Environment, Anhui University of Science and Technology, Huainan 232001, China

\section{Supporting Information}

\begin{abstract}
This research developed an innovative approach to reveal nitrogen sources, transformation, and transport in large and complex river networks in the Taihu Lake basin using measurement of dual stable isotopes of nitrate. The spatial patterns of $\delta^{15} \mathrm{~N}$ corresponded to the urbanization level, and the nitrogen cycle was associated with the hydrological regime at the basin level. During the high flow season of summer, nonpoint sources from fertilizer/ soils and atmospheric deposition constituted the highest proportion of the total nitrogen load. The point sources from sewage/manure, with high ammonium concentrations and high $\delta^{15} \mathrm{~N}$ and $\delta^{18} \mathrm{O}$ contents in the form of nitrate, accounted for the largest inputs among all sources during the low flow season of
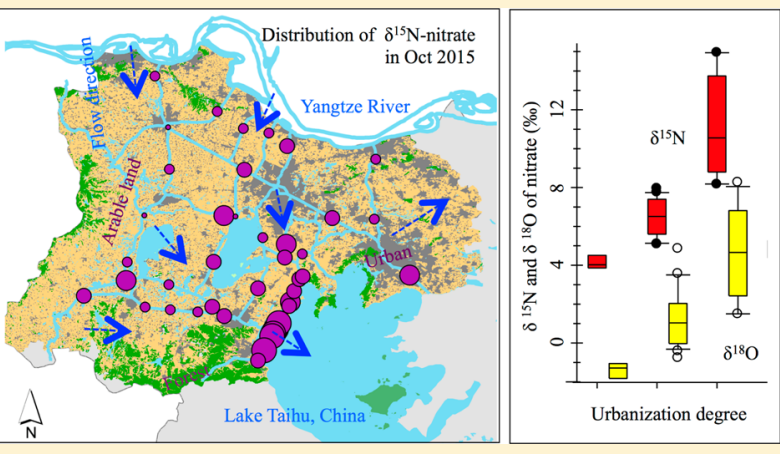
winter. Hot spot areas with heavy point source pollution were identified, and the pollutant transport routes were revealed. Nitrification occurred widely during the warm seasons, with decreased $\delta^{18} \mathrm{O}$ values; whereas great potential for denitrification existed during the low flow seasons of autumn and spring. The study showed that point source reduction could have effects over the short-term; however, long-term efforts to substantially control agriculture nonpoint sources are essential to eutrophication alleviation for the receiving lake, which clarifies the relationship between point and nonpoint source control.
\end{abstract}

\section{INTRODUCTION}

Over the past century, surplus nitrogen $(\mathrm{N})$ has been loaded into the biosphere due to intensive anthropogenic activities, resulting in excessive nitrogen in surface water and contributing to water quality impairment, eutrophication, and ecological disasters. ${ }^{1,2}$ Reduction of extra nitrogen load is the fundamental way to improve water quality and restore aquatic ecosystems. Strong efforts to identify nitrogen pollution sources entering into rivers and lakes have been attempted in the past several decades. $^{2-4}$ Nitrogen sources are classified into point sources and nonpoint sources. Traditionally, point sources come from domestic sewage, industry discharge, and livestock manure, and nonpoint sources come from agricultural fertilizer, soil erosion, and atmospheric dry and wet deposition. There are many methods for identifying nitrogen sources and load from a watershed to the receiving waters. In general, the point source pollution load can be obtained through detailed statistics, whereas the nonpoint source pollution load from a catchment is estimated by watershed models. ${ }^{5-7}$

Despite great efforts to identify point source or nonpoint source pollution related to different land use, ${ }^{8,9}$ nitrogen source identification remains challenging in urbanized and industrialized areas with complex land use. The problem is intensified where densely crisscrossed river networks are concerned; complicated flow patterns make nitrogen transport processes difficult to trace. ${ }^{10}$ Although some researchers correlate nitrogen in waters with land use using statistical approaches, ${ }^{11,12}$ the results are qualitative with great uncertainty. The relationship between complex source loading and water quality in plain river networks is not sufficient to support basinscale nitrogen management. Consequently, many lakes suffer high external nutrient inputs and algal blooms. ${ }^{13,14}$

The dual isotope (combination of ${ }^{15} \mathrm{~N}$ and ${ }^{18} \mathrm{O}$ in nitrate) approach has been applied to trace sources of nitrate and their potential transformation from atmospheric deposition, soils, chemical fertilizers, and sewage or manure, both in surface and groundwater. ${ }^{2,15-22}$ The application fields cover different types of land use, including forested, ${ }^{15,16}$ agricultural, ${ }^{17}$ urbanized, and hybrid areas. ${ }^{18-22}$ During recent years, the analytical methodologies for both $\delta^{15} \mathrm{~N}$ and $\delta^{18} \mathrm{O}$ have improved considerably, and have become an attractive technique to identify nitrogen sources in surface or groundwater. ${ }^{23,24}$ However, adapting the method to identify nitrogen sources in complex plain river networks, which have variable spatiotem-

Received: December 11, 2016

Revised: April 17, 2017

Accepted: April 20, 2017

Published: April 20, 2017 
poral nitrogen loading patterns, from an integrated basin-scale perspective remains highly ambitious.

The main objectives of this work are to (1) develop a comprehensive approach by combining analysis of water quality and dual isotopes of nitrate to identify the dominant sources and transformation processes of nitrogen in complex river networks of a lake basin; (2) reveal spatial distribution patterns and transport routes of nitrate in complex river networks with relation to land use and hydrological regime; (3) quantify the potential for reduction of nitrogen, and evaluate the effectiveness of nutrient management strategy at a basin scale for alleviation of lake eutrophication.

\section{MATERIALS AND METHODS}

Study Area. Lake Taihu is the third largest freshwater lake in China. It covers an area of $2338 \mathrm{~km}^{2}$ with an average depth of $1.9 \mathrm{~m}$ and a corresponding volume of 4.4 billion $\mathrm{m}^{3}$. The Taihu basin has an area of approximately $36895 \mathrm{~km}^{2}$ and is located in the downstream area of the Yangtze River (Figure 1).

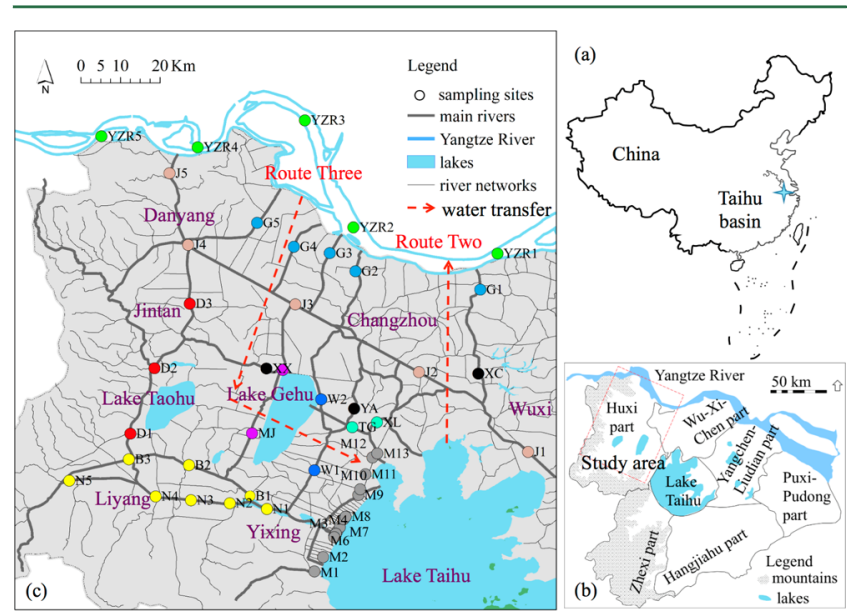

Figure 1. Location of study areas ( $a, b)$, and sampling sites (c) in the upstream river network of Lake Taihu. (Note: the river network is simplified from more complex rivers; "Route Two" and "Route Three" refer to the Water Transfer Projects between the Yangtze River and Lake Taihu, and the arrows indicate water transfer directions.)

The basin is heavily populated and highly industrialized, with only $0.4 \%$ of China's land area supporting 40 million residents and $11 \%$ of the Gross Domestic Product of the country. The lake suffers serious eutrophication and cyanobacterial blooms due to excessive external nutrient loading from the Taihu basin. The intensified land-use of industrialization, urbanization and agriculture in the basin has produced high nitrogen loading from multiple sources. ${ }^{10,12}$ Consequently, two-thirds of the lake area exceeds the level of $1.0 \mathrm{mg} \mathrm{L}^{-1}$ total nitrogen and $0.05 \mathrm{mg}$ $\mathrm{L}^{-1}$ total phosphorus, the nutrient concentration thresholds for controlling eutrophication in Lake Taihu required by the government.

The basin is divided into eight parts in terms of hydraulic characteristics (Figure 1b), and the river network is well developed, consisting of over 200 main rivers crisscrossing the basin. This study focuses on the upstream areas in the northwest of the Taihu basin, covering the whole area of the Huxi part and half the area of the $\mathrm{Wu}-\mathrm{Xi}$-Chen part (Figure 1b). These two parts are the most heavily polluted areas and account for over $70 \%$ of the pollution loads entering into the lake. The west and south are the upstream rivers along with mountains, and the north is bounded by the Yangtze River. Plain river networks characterize the hydraulics of the study areas, where west-east rivers crisscross with north-south rivers. Specific information on Taihu basin climate, hydrology and river networks in the study area can be found in the Supporting Information (SI) or literature. ${ }^{10}$

Sampling Design. Forty-eight sampling sites are located in the main rivers (Figure 1c). Specific information concerning sampling sites is listed in (SI Table S1). Three sampling campaigns were conducted in the high flow season of summer, low flow season of autumn, and low flow season of winter in late June 2015, October 2015, and January 2016, respectively. Monthly samplings from June 2015 to April 2016 were conducted in the 13 main inflowing rivers to obtain more details on the nitrogen loading patterns. Water samples were collected at the Yangtze River sites in June of 2015 and January of 2016. The details of the hydrological regime of the study area are shown in Figure S1 in SI. Water volume at Lake Taihu reached its peak in the heavily rainy June of 2015, declined toward the low flow of autumn and winter, and increased with rainfall events in the spring of 2016.

Water Quality and Stable Isotope Analysis. Surface water samples were taken at $0.5-1.0 \mathrm{~m}$ depth under the surface using a $5 \mathrm{~L}$ Plexiglas water sampler. The main analyzed parameters included water temperature, $\mathrm{pH}$, dissolved oxygen, electricity conductivity, total nitrogen, total dissolved nitrogen, dissolved inorganic nitrogen forms of nitrate, nitrite and ammonium, and chloride. Details on sampling methods and water quality analysis are provided in SI.

Collected river samples for stable isotopic analysis were filtered with $0.2 \mu \mathrm{m}$ cellulose ester filters and frozen below -20 ${ }^{\circ} \mathrm{C}$ until analysis. The denitrifier method at the Environmental Stable Isotope Lab in Chinese Academy of Agricultural Sciences (CAAS), Beijing was used for analyzing $\delta^{15} \mathrm{~N}$ and $\delta^{18} \mathrm{O}$ in nitrate. Briefly, denitrifying bacteria (Pseudomonas auroeofaciens) convert nitrate to gaseous nitrous oxide $\left(\mathrm{N}_{2} \mathrm{O}\right)$, detected using an isotope ratio mass spectrometer (TracegasIsoprime100, Germany). Isotopic ratio values are reported in parts per thousand (\%o) relative to atmospheric $\mathrm{N}_{2}$ and Vienna Standard Mean Ocean water (VSMOW) for $\delta^{15} \mathrm{~N}$ and $\delta^{18} \mathrm{O}$, respectively:

$$
\Delta_{\text {sample }}(\%)=\left[\left(R_{\text {sample }}-R_{\text {standard }}\right) / R_{\text {standard }}\right] \times 1000
$$

where $\Delta_{\text {sample }}$ is the stable isotope ratio in the samples, $R_{\text {sample }}$ is the ratio of ${ }^{15} \mathrm{~N} /{ }^{14} \mathrm{~N}$ or ${ }^{18} \mathrm{O} /{ }^{16} \mathrm{O}$ in the samples, $R_{\text {standard }}$ is the ratio of ${ }^{15} \mathrm{~N} /{ }^{14} \mathrm{~N}$ or ${ }^{18} \mathrm{O} /{ }^{16} \mathrm{O}$ in the standards. Sample analysis had an average precision of $0.2 \%$ for $\delta^{15} \mathrm{~N}$-nitrate and $0.7 \%$ 。 for $\delta^{18} \mathrm{O}$-nitrate.

The land use of 2010, combined with the hydrological regime (Figure S1 and Table S2 in SI), of the study area was used to analyze their effects on spatial patterns of dual isotopes of nitrate. Sampling sites at the downstream of the flow direction were selected for statistical analysis. Pearson correlation coefficients, at confidence levels of 95\% ( $p<$ $0.05)$ and $99 \%(p<0.01)$, were used to analyze relationships between water quality, $\delta^{15} \mathrm{~N}$-nitrate and $\delta^{18} \mathrm{O}$-nitrate.

Estimates of Different Source Contributions. The contributions of different sources were estimated for the 13 main inflowing rivers (M1 M13) of Lake Taihu, whereas other surrounding inflowing rivers are blocked by water locks for management purposes. The isotopic data in the inflowing rivers were consistent across all sources after experiencing biological transformation in the upstream drainage areas and 
river networks. Monte Carlo Markov Chain (MCMC) methods for solving mixing models infer the contribution of different food sources of organisms in the food web, ${ }^{25,26}$ and help estimate pollution sources of nitrate to surface water. ${ }^{18,27}$ This mixing model analysis was implemented with the "SIAR" (Stable Isotope Analysis in R) package. Individual water samples were treated as "organisms" and nitrate sources were treated as "food sources" to determine proportional source contributions.

The nitrogen sources were estimated for the three sampling periods, the high flow season of summer, low flow season of autumn, and low flow season of winter. The end-members for different nitrate sources in the mixing model were selected considering the distribution of dual isotopic data and hydrological regime across the sampling periods. Being an additional marker, the $\delta^{18} \mathrm{O}$-nitrate has negative or no effect on $\delta^{15} \mathrm{~N}$-nitrate for nitrate source identification in sewage/manure, but it does have a positive contribution to identification of nitrate precipitation or synthetic nitrate fertilizer from other sources. ${ }^{23}$ Therefore, $\delta^{18} \mathrm{O}$-nitrate of end-member was only used in the mixing model for source estimate during summer. The end-members of $\delta^{15} \mathrm{~N}$ and $\delta^{18} \mathrm{O}$ for sewage/manure sources were calculated based on samples of inflow and outflow at one wastewater treatment plant in the Changzhou City, where a relevant study was conducted focusing on the endmembers of raw sewage and treated sewage in the areas. ${ }^{29} \delta^{15} \mathrm{~N}$ was stable across the three sampling periods in agriculturedominated areas, and an end-member was designated according to the statistics of 10 samples from upstream agricultural areas in the winter. The end-member of $\delta^{18} \mathrm{O}$ in soils during summer was designated the same as the sewage/manure source, both of which experience microbial processes, different from $\delta^{18} \mathrm{O}$ in atmospheric deposited nitrate during the summer. The endmembers of $\delta^{15} \mathrm{~N}$ and $\delta^{18} \mathrm{O}$ for atmospheric deposited nitrate were calculated from three collected samples in this research and four collected samples in a relevant study conducted in summer. ${ }^{28}$ Contribution of fractional corrections was not included in the mixing model; however, the effects of fractionation on estimating the contribution of different sources was evaluated, which is elaborated in the Discussion section. Details of end-members selection for the mixing models in each season were presented in Table S3 in SI.

\section{RESULTS}

Spatial Patterns of Nitrogen Concentration and Forms. Water quality parameters varied remarkably across the river networks in the upstream basin due to different degrees of pollution (Table S4 in SI). Total nitrogen concentration ranged from 3.4 to $5.1 \mathrm{mg} \mathrm{L}^{-1}$ on average, which was far over the $2.0 \mathrm{mg} \mathrm{L} \mathrm{m}^{-1}$ threshold for controlling nutrient loading in river networks of Taihu Lake basin. Dissolved total nitrogen accounted for more than $70 \%$ of the total nitrogen, mainly in dissolved inorganic nitrogen forms. Nitrate accounted for the largest proportion of dissolved inorganic nitrogen at approximately $67-82 \%$, followed by ammonium and then nitrite.

The total nitrogen concentration was higher during the low flow season of winter than that in the other two seasons, with $5.1 \mathrm{mg} \mathrm{L}^{-1}$ in January of 2016 versus $3.4 \mathrm{mg} \mathrm{L}^{-1}$ and $3.5 \mathrm{mg}$ $\mathrm{L}^{-1}$ in June and October of 2015 in average. (Table S4 and Figure S2 in SI). The ammonium concentration increased from upstream to downstream in the river network. The averaged total nitrogen concentration at sampling sites along the Yangtze
River was about $1.9 \mathrm{mg} \mathrm{L}^{-1}$, but increased to $5.9 \mathrm{mg} \mathrm{L}^{-1}$ at sampling sites of inflowing river mouths during winter low flow. In particular, the heaviest nitrogen pollution occurred in industrialized and urbanized downstream areas such as Wuxi City, Changzhou City, and Yixing City, which had a higher ratio of ammonium to dissolved inorganic nitrogen in winter than in the other two seasons (Figure S3 in SI).

The ammonium concentration in all three seasons correlated positively to chloride ion concentration (Figure S4 in SI), which might indicate anthropogenic pollution, especially from manure or sewage sources, due to the biogeochemical inactivity of chloride.

Seasonal Patterns for Nitrogen and Oxygen Isotopes of Nitrate. Ranges of $\delta^{15} \mathrm{~N}$ in the three periods did not show obvious differences, with $+4.2 \%$ to $+14.9 \%$, $+1.7 \%$ to $+14.9 \%$, and $+2.7 \%$ o to $+11.6 \%$ in June, October of 2015 , and January of 2016, respectively. Dual $\delta^{15} \mathrm{~N}$ and $\delta^{18} \mathrm{O}$ source plots showed that nitrate in the upstream area of Lake Taihu came mainly from ammonium in fertilizer/rain, soils and sewage (Figure 2). The $\delta^{18} \mathrm{O}$ data implied a substantial transformation

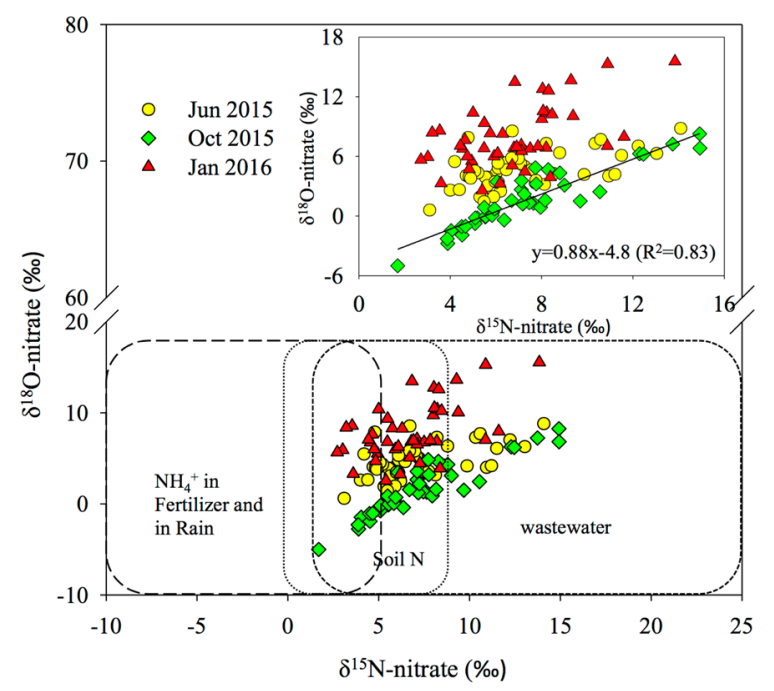

Figure 2. Dual $\delta^{15} \mathrm{~N}$-nitrate and $\delta^{18} \mathrm{O}$-nitrate source plots for water samples collected during June of 2015, October of 2015 and January of 2016. (Note: The linear relationship in the enlarged figure refers to Oct 2015; the boxes of dash lines indicates typical ranges in isotopic signatures for various sources according to Kaushal et al. ${ }^{2}$ and Xue et $\left.\mathrm{al.}^{23}\right)$.

of nitrogen in soils, rivers or wastewater treatment plants, which decreased greatly during warm seasons. Interestingly, a positive linear relationship between $\delta^{15} \mathrm{~N}$ and $\delta^{18} \mathrm{O}$ with a slope of 0.9 was observed during autumn, which indicates denitrification. Further confirmation is needed because of the great heterogeneity in such a large-scale basin with multisources.

Spatial Patterns of Nitrogen and Oxygen Isotopes of Nitrate. The analysis of $\delta^{15} \mathrm{~N}$ showed clear effects of urbanization on nitrate pollution, whereas the $\delta^{18} \mathrm{O}$ data showed more spatial variability across the three sampling periods (Figure 3 and Figure 4, Figure S6 and Figure S7 in SI).

The nitrogen pollutants in upstream rivers came from areas dominated by agricultural land, reflecting the lower values of $\delta^{15} \mathrm{~N}$ of soil sources. The values of $\delta^{15} \mathrm{~N}$ increased due to mixing with more sewage/manure sources when the flow passed through small cities or townships in midstream, and finally reached the highest values in the highly urbanized areas 


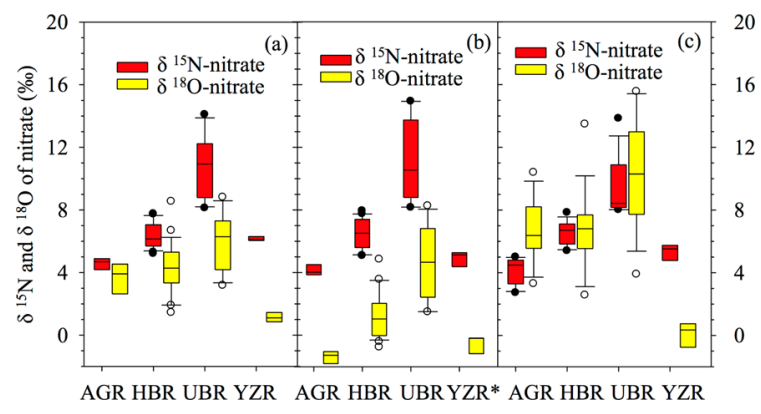

Figure 3. Statistics of dual isotopes of nitrate for sampling sites grouped into three categorized areas according to land use in June (a), October (b) of 2015, and January (c) of 2016. (Note: AGR represents agricultural areas; HBR represents hybrid areas of agricultural land, small cities or populated towns; UBR represents highly urbanized areas; YZR represents the Yangtze River. The statistics for YZR in October of 2015, indicated by YZR* in panel b, was calculated by using samples from rivers G1, G3 G5, and J5, through which water from the Yangtze River was diverted into the river networks during this month. Intervals of boxplots show the 10th, 25th, median, 75th, and 90th percentiles with outliers for each categorized area.).

in the downstream of Yixing City, Changzhou, and Wuxi City (Figure 1). During winter with low temperature (Table S4 in $\mathrm{SI}$ ), high values of $\delta^{18} \mathrm{O}$ (Figure $4 \mathrm{~b}$ and Figure 3c) occurred in most sampling sites. During summer with high temperature, decreased $\delta^{18} \mathrm{O}$ suggested that nitrification is common in soils, rivers or wastewater treatment plants (Figure 3a and SI Figure S6b). The $\delta^{18} \mathrm{O}$ in October of 2015 dropped further compared to summer, due to dilution by the diverted water from Yangtze River with low $\delta^{18} \mathrm{O}$ signatures (Figure $3 \mathrm{~b}$ and SI Figure S7b).

The linear relationship of a fixed ratio of 0.9 between $\delta^{15} \mathrm{~N}$ and $\delta^{18} \mathrm{O}$ in October of 2015 (Figure 2) is evaluated spatially at a basin scale. The sampling sites with both low $\delta^{15} \mathrm{~N}$ and $\delta^{18} \mathrm{O}$ along the linear line were located in the upstream rivers, with more soil-sourced nitrate from agricultural areas, and receiving diverted water from the Yangtze River. The enrichment of both $\delta^{15} \mathrm{~N}$ and $\delta^{18} \mathrm{O}$ is concentrated in downstream sites from M3 to
M8, where nitrate concentration was in the low range of $0.5-$ $1.5 \mathrm{mg} \mathrm{L}^{-1}$. This pattern showed probable high denitrification potential in sewage from the Yixing City and its adjacent industrialized towns (Figure S7 in SI).

Monthly Patterns of Total Nitrogen and Dual Isotopic Values of Nitrate in Inflowing Rivers. The monthly variation of total nitrogen in the 13 inflowing rivers matched well with the hydrological rhythm of the basin (Figure 5). The

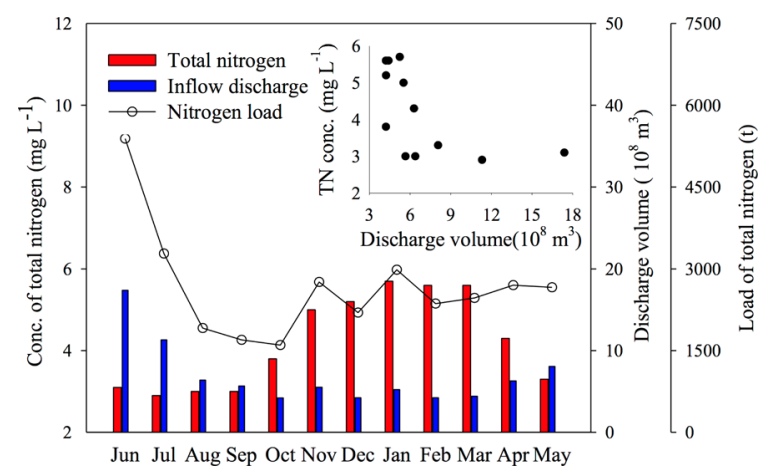

Figure 5. Flow weighted concentration of total nitrogen $(\mathrm{TN})$ versus discharge from the Huxi part to the lake through inflowing rivers during June of 2015 to May of 2016.

lowest total nitrogen concentration of $2.9 \mathrm{mg} \mathrm{L}^{-1}$ occurred during high flow in summer, which increased to $5.7 \mathrm{mg} \mathrm{L}^{-1}$ during low flow in winter, reflecting the effects of runoff dilution.

Spatial patterns of dual isotopic values of nitrate in the inflowing rivers (Figure S8 in SI) show obvious spatial clusters. The $\delta^{15} \mathrm{~N}$ peak values for the year were concentrated in the inflowing river mouth near Yixing City. The spatial and temporal variations of $\delta^{18} \mathrm{O}$ were complex due to biological nitrogen transformation, and mixing with storm flow or diverted water from the Yangtze River. During the autumn and spring, denitrification resulted in a linear trend of about a 1:1 ratio between $\delta^{15} \mathrm{~N}$ and $\delta^{18} \mathrm{O}$ (Figure S9 in SI), with a

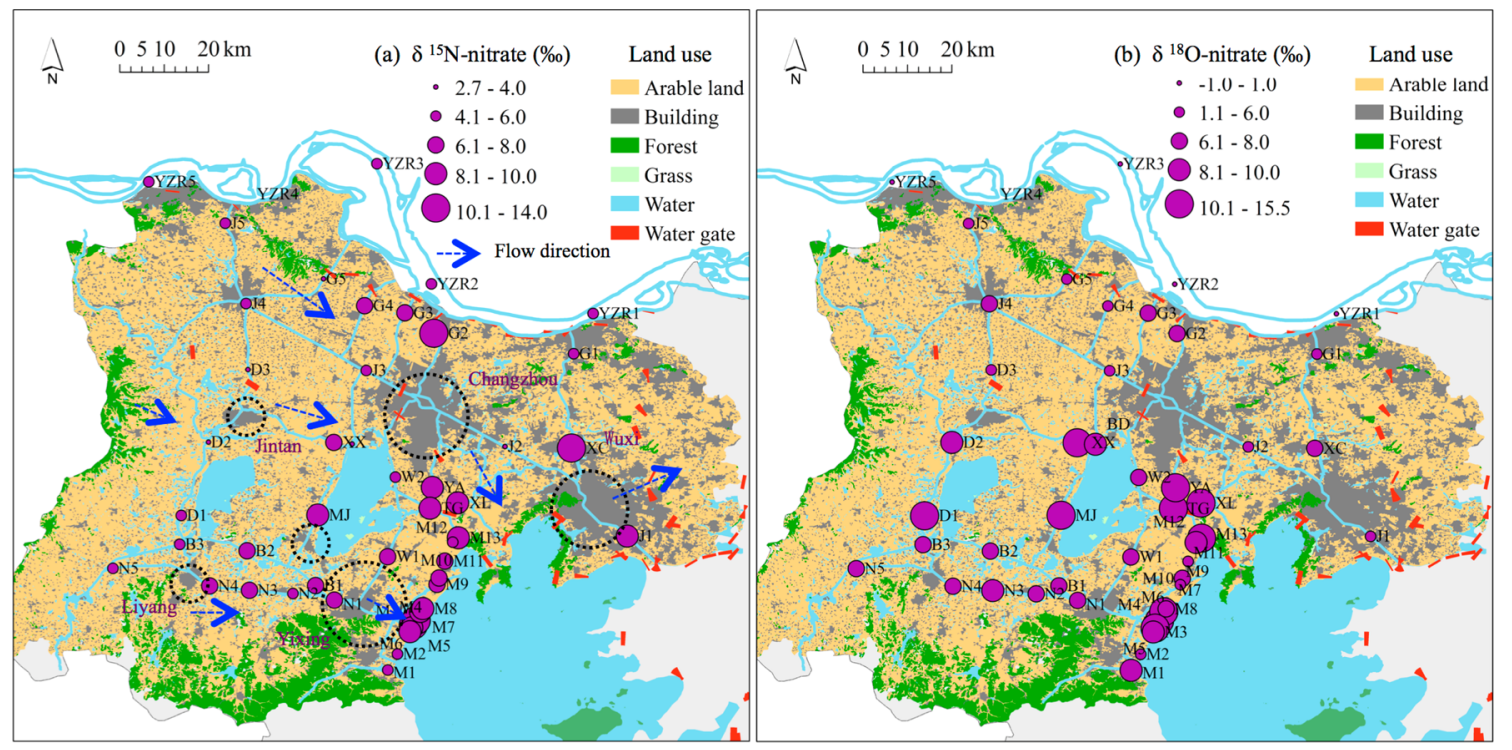

Figure 4. Spatial distribution of $\delta^{15} \mathrm{~N}$-nitrate (a) and $\delta^{18} \mathrm{O}$-nitrate (b) in the upstream river networks of Lake Taihu during the low flow winter in January of 2016. (Note: dashed circles represent the hot spot areas heavily polluted with sewage/manure sources as elaborated in the Discussion section.). 
significant decrease in concentrations of total nitrogen and nitrate compared to winter (Figure 5 and Figure S10 in SI).

Proportion of Sewage/Manure Sources. The proportion of atmospheric deposit-sourced nitrate is less variable due to its high $\delta^{18} \mathrm{O}$ signals, in the range of $5-10 \%$. The spatial patterns for sewage/manure proportion along the inflowing rivers corresponded well to the $\delta^{15} \mathrm{~N}$ spatial patterns (Figure S8 in SI). Higher pollution from sewage/manure sources was concentrated in downstream sampling sites of Yixing City (M5-M9). The averaged proportions of sewage/manuresourced nitrate were $40 \%, 59 \%$, and $47 \%$ in June, October, and January, respectively. The sewage/manure-sourced nitrate proportion increased from summer to autumn (Figure 6a and b) along the decrease of discharge, and it decreased again in winter (Figure 6c) due to weak nitrification.

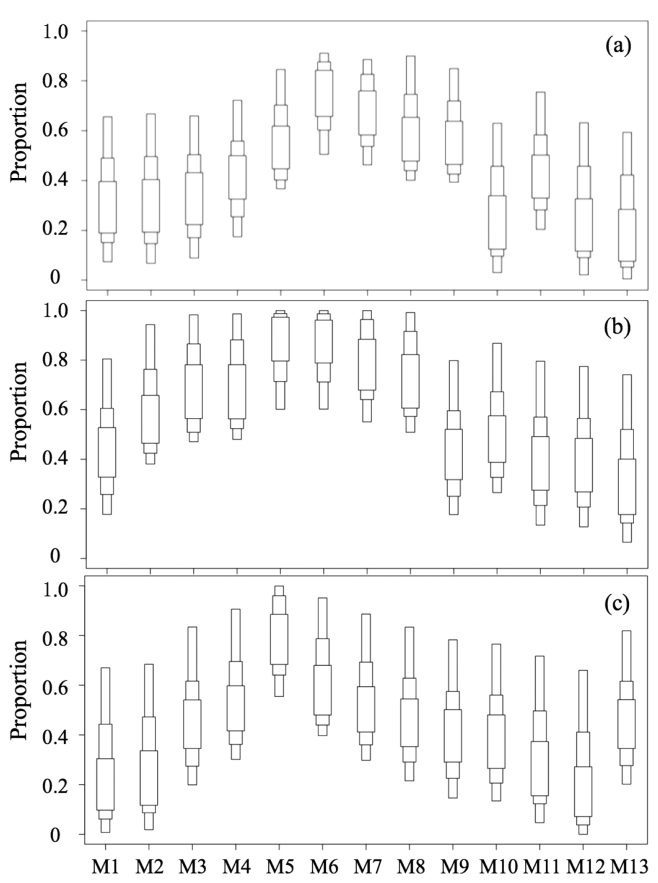

Figure 6. Proportion of sewage/manure sourced nitrate in all nitrate sources in the 13 (M1-M13) inflowing rivers in June (a), October (b) of 2015, and January (c) of 2016. Intervals show the $0.05,0.25,0.75$, and 0.95 Bayesian credible intervals for the probability distribution calculated for each source.

\section{DISCUSSION}

Nitrogen Sources and Transformation in the Taihu Basin. A previous study estimated that point sources and nonpoint sources contributed equally to the nutrient load entering into Lake Taihu. ${ }^{8}$ In this study, the relative contribution of each source changing with land use and hydrological regime in the plain river networks was clarified effectively using the stable isotope approach combined with nitrogen spatiotemporal distribution patterns.

During the low flow season of winter, about $47 \%$ of nitrate from the sewage/manure source was estimated. The point source pollution problems are accentuated due to weak biological transformation in winter, when higher concentrations of total nitrogen and ammonium occurred compared to summer and autumn. This result is comparable to those in previous studies conducted in some sub-basins or small catchments in the Taihu basin. ${ }^{28,30}$ During the low flow season, the isotope signals at sampling sites in rural areas are comparable to those in soil drainage experiencing nitrification, ${ }^{31-33}$ differentiating it from less-transformed sewage/ manure sources.

During the high flow season of summer, nitrification results in $\delta^{18} \mathrm{O}$ depletion in nitrate both in the basin and in concentrated inflowing rivers. Denitrification is weak during high flow, leading to less retention in the soils, rivers or wastewater treatment plants due to the flushing-out effect. ${ }^{2} \mathrm{~A}$ recent research study conducted at the scale of an nitrogensaturated subtropical forested catchment indicated that both nitrification and denitrification were strongly impacted by heavy storm events, resulting in sharp declines in nitrate concentration and decreased denitrification efficiency. ${ }^{34}$ A $40 \%$ proportion of nitrate was estimated from sewage/manure sources in June of 2015. The runoff-flushed atmospheric deposited nitrogen, which accumulated on impervious surfaces during dry periods, led to high ammonium concentrations in downstream cities and towns via sewer overflows (SI Figure S3). In this research, 5-10\% nitrate from atmospheric deposition during high flow was estimated by the mixing model. If ammonium or other nitrogen forms were counted, atmospheric deposition would contribute $10-20 \%$ to nitrogen loading, which accounted for $16.5 \%$ of annual nitrogen loading via inflowing rivers from wet deposition in the Taihu basin. ${ }^{35}$

During autumn and spring, the soil-induced nitrate from fertilizer/rain decreased due to weak agricultural activities and few rainfall events. The linear relationships between $\delta^{15} \mathrm{~N}$ and $\delta^{18} \mathrm{O}$ (SI Figure S9) in the inflowing rivers could indicate different degrees of denitrification occurrence across a largescale basin with spatial heterogeneity. Denitrification could occur in subsoil, the riparian or hyporheic zone, and the stream channel. ${ }^{2,34,36}$ In addition, denitrification in wastewater treatment plants plays an important role in reducing nitrogen load, verified by enrichment of $\delta^{15} \mathrm{~N}$ and $\delta^{18} \mathrm{O}$ toward the denitrification line.

However, multiple sources of uncertainty associated with the mixing model should be acknowledged, and the mixing model results should be interpreted with caution. ${ }^{2}$ One uncertainty is that some sources, such as atmospheric deposited nitrate during the seasons of autumn and winter, synthetic nitrate fertilizer, and source of diverted water from the Yangtze River, were not counted. Selection of isotopic end-members of different sources would also contribute uncertainty to the mixing model across a basin with spatial heterogeneity and different land use, as presented by the variability of sewage/manure sources in Figure 6. Moreover, biological nitrogen transformation, such as nitrification and denitrification, could result in overestimation or underestimation of sewage/manure proportion in different seasons. For example, the sewage/manure proportion could be overestimated when less-nitrified sewage/manure in winter or substantially denitrified sewage in warm season was discharged, because their $\delta^{15} \mathrm{~N}$ of the end-member for sewage/manure sources should bias larger values. Denitrification potential along the flow paths in river networks could also result in overestimated proportion of sewage/manure sources because the denitrified water samples would have enriched $\delta^{15} \mathrm{~N}$ values, which needed to be further clarified.

Despite the limits and uncertainties, the research results provided insights to the understanding of the nitrogen cycle at a basin affected by intensive human activities. For nitrogen loading processes, the relative contribution of point sources versus nonpoint sources changed dynamically with the 
hydrological regime. During the high flow season, nonpoint sources from agriculture and atmospheric deposition resulted in the increase of nitrogen load. The load of total nitrogen at the Huxi Part in the rainy month of June was over 5000 tons; whereas it was slightly less than 3000 tons through the winterspring season, when point sources were predominant (Figure 5). The contribution of denitrification to nitrogen removal in the rainy season was limited due to storm flow impacts. Favorable conditions for nitrification and denitrification were created during the low flow but warmer seasons of autumn and spring. The monthly averaged load of total nitrogen from August to October is about 1700 tons, decreasing $40 \%$ compared to that during the winter season (Figure 5).

Nitrogen-Polluted Hot Spot Areas with Heavy Sewage/Manure Source and Its Transport Routes. In a large-scale basin, spatial patterns of nitrogen concentration, forms and isotope signals could indicate the relative importance of different sources, and trace their mixing and transport routes. The areas with heavy nitrogen pollution by sewage/manure sources were in the downstream of the study area. Changzhou City, Wuxi City, and Yixing City are the hot spot areas, which should be the focus for nitrogen control. The nitrogen source from the sewage of urbanized towns and cities substantially increased the nitrogen load in the rivers flowing across the areas, and there is little buffer zone for pollutant retention or removal as these areas are adjacent to the lake. Further details on the hot spot areas can be found in the relevant data from other studies. $^{28,30,37,38}$

The nitrogen mixing and transport routes differ with the hydrological regimes in different seasons. Generally, the upstream areas from the north, west, and south of the basin boundary produce lower concentrations of nitrate, with a higher proportion of soil sources. These sources were mixed with higher proportions of sewage/manure sources in the midstream after flowing through the main cities. Finally, water drained into Lake Taihu through the 13 main inflowing rivers, by mixing higher proportions of sewage/manure sources from hot spot areas in the downstream.

During the high flow period, most water from the Yangtze River or its adjacent upstream areas is passed through the Beijing-Hangzhou Great Canal, flushing pollutants from Changzhou City and Wuxi City toward downstream or the Yangtze River through the coastal rivers (SI Figure S6a), causing less impact on the water quality of the lake. During low flow seasons, pollutants from the downstream Changzhou City and Wuxi City are discharged mainly into the lake (Figure 4a and SI Figure S7a).

Implications for Nitrogen Reduction in the Upstream Basin. The ratio between nitrogen and phosphorus $(\mathrm{N}: \mathrm{P})$ and the response of algal blooms are the central issues of concern to scientists and local governments, because they relate to the nitrogen reduction strategy in the basin. Recent research in the inner lake using a bioassay method indicated that Lake Taihu shifts from phosphorus limitation in winter-spring to nitrogen limitation in cyanobacteria-dominated summer and fall, and that nitrogen load reduction in the hyper-eutrophic system of Lake Taihu must be performed. ${ }^{39-42}$ The limitation patterns of algae growth responded to nutrient loading from the basin. Lower nitrogen concentrations occurred in inflow in summerfall seasons (Figure 5), and more internal phosphorus could be released from the sediments under conditions of high temperature or strong wind-induced hydraulic disturbance in the lake. This could lead to lower N:P ratios in the lake and nitrogen limitation on algal growth. During winter-spring, high-nitrogen-concentration water enters the lake from the inflowing rivers, but phosphorus deposits toward the bottom with dead algae, leading to phosphorus limitation. Moreover, phosphorus control activities in recent years have reduced phosphorus availability and promoted the relative accumulation of nitrogen in large lakes, resulting in arguments for greater removal of nitrogen as well as phosphorus sources. ${ }^{43,44}$ Therefore, both nitrogen and phosphorus control are important in reducing their magnitude during warmer seasons in lakes.

Furthermore, experiments on how nutrients limit algae growth using nutrient dilution and enrichment bioassays concluded that $20-41 \%$ phosphorus and $61-71 \%$ nitrogen must be reduced to bring the phytoplankton biomass of Lake Taihu to an "acceptable" sub-bloom level of less than $20 \mu \mathrm{g} \mathrm{L}^{-1}$ chlorophyll $a^{45}$ The bioassay method indicated that the threshold concentration of total nitrogen and total phosphorus should be targeted at below $0.80 \mathrm{mg} \mathrm{L}^{-1}$ and $0.05 \mathrm{mg} \mathrm{L}^{-1}$, respectively, to limit the intrinsic growth rates of Microcystisdominated algae. This task seems impossible in the short term, especially for nitrogen reduction. According to the source estimation, $40-59 \%$ sewage-associated sources of nitrate entered into Lake Taihu. Even a complete cessation of point source pollution could not meet the requirements for nitrogen control. Therefore, a substantial control of agricultural nonpoint source pollution will be the determining factor for mitigating algal blooms in a long-term effort.

According to this study, nitrification and denitrification of wastewater are crucial in the identified hot spot areas. Enhanced nitrification would further decrease ammonium and dissolved free amino acids, which are more efficiently taken up by CyanoHAB organisms (e.g., Microcystis) than nitrate. ${ }^{40}$ Denitrification would reduce the nitrogen load to the lake, leading to decreased algal biomass. A stricter standard for discharge of wastewater treatment plants was launched in the Taihu basin in 2008, through which more reduction of ammonium and total nitrogen could be expected. Moreover, effluent from wastewater treatment plants could be further treated in the future, focusing on nitrogen removal. Although improving discharge standards results in high cost, it is achievable in such a highly developed region.

For the control of nonpoint sources or diffuse point source pollution, the denitrification potential inside the basin should be enhanced. Plenty of water zones, accounting for $12 \%$ of the study area (as shown in Figure 4), provide possible buffers for nitrogen retention, which are important for nitrogen removal. ${ }^{34,46}$ In particular, reduction of nitrogen from nonpoint source pollution in agricultural areas, which produces high nitrogen levels in base flow, is essential. Ecological engineering practices, such as wetlands, ponds, and grass channels in riverine areas, could play important roles in nitrogen reduction as a long-term strategy.

From the hydrological perspective, a possible approach is to transfer less-polluted water for dilution of pollutants in the lake, such as the Water Transfer from the Yangtze River to Lake Taihu project. ${ }^{44,47,48}$ This project is becoming controversial because the nitrogen concentration in the Yangtze River is higher than the average value of Lake Taihu. ${ }^{49}$ Given the fact that water transfer could improve hydrodynamic conditions in the lake, ${ }^{50}$ more efficient water transfer plans are expected (see Route Two and Route Three for water transfer in Figure 1). However, the ecological, energy and economic issues related to water transfer need to be well evaluated. In any case, the similar 
nitrogen level in the Yangtze River to that from nonpoint source pollution in the basin means that water transfer could not result in nitrogen reduction, thus better effects could only be achieved by intercepting drainage of high-nitrogen concentration toward the lake.

\section{ASSOCIATED CONTENT}

\section{S Supporting Information}

The Supporting Information is available free of charge on the ACS Publications website at DOI: 10.1021/acs.est.6b06278.

Details of climate and hydrological characteristics of Taihu Lake basin; methods for water quality analysis; list of rivers and sampling sites; information on land use and end-members for the mixing model; Hydrological regime, water quality, spatial distribution of total nitrogen, dissolved inorganic nitrogen forms, dual isotopes of nitrate; relationships between chloride ion and total nitrogen and ammonium; $\delta^{15} \mathrm{~N}$-nitrate versus nitrate concentration plots; monthly data of $\delta^{15} \mathrm{~N}$-nitrate and $\delta^{18} \mathrm{O}$-nitrate, and dissolved inorganic nitrogen in the inflowing rivers; $\delta^{15} \mathrm{~N}$-nitrate versus $\delta^{18} \mathrm{O}$-nitrate plots for water samples in the inflowing rivers (PDF)

\section{AUTHOR INFORMATION}

\section{Corresponding Author}

*Phone/fax: +86 25 85829765; e-mail: qchen@nhri.cn.

ORCID ${ }^{\circ}$

Qiuwen Chen: 0000-0003-0905-7591

\section{Notes}

The authors declare no competing financial interest.

\section{ACKNOWLEDGMENTS}

This research was supported by the National Nature Science Foundation of China (No. 91547206, 51425902) and Jiangsu Water Resources Department (No. 2015005, GHB-HT-2016). We are grateful to Dr. Catherine Rice for proofreading the manuscript.

\section{REFERENCES}

(1) Vitousek, P. M.; Aber, J. D.; Howarth, R. W.; Likens, G. E.; Matson, P. A.; Schindler, D. W.; Schlesinger, W. H.; Tilman, D. G. Human alteration of the global nitrogen cycle: Sources and consequences. Ecol. Appl. 1997, 7 (3), 737-750.

(2) Kaushal, S. S.; Groffman, P. M.; Band, L. E.; Elliott, E. M.; Shields, C. A.; Kendall, C. Tracking nonpoint source nitrogen pollution in Human-Impacted Watersheds. Environ. Sci. Technol. 2011, 45 (19), 8225-8232.

(3) Mayer, B.; Bollwerk, S. M.; Mansfeldt, T.; Hütter, B.; Veizer, J. The oxygen isotope composition of nitrate generated by nitrification in acid forest floors. Geochim. Cosmochim. Acta 2001, 65 (16), 27432756.

(4) Anisfeld, S. C.; Barnes, R. T.; Altabet, M. A.; Wu, T. X. Isotopic apportionment of atmospheric and sewage nitrogen sources in two connecticut rivers. Environ. Sci. Technol. 2007, 41 (18), 6363-6369.

(5) USEPA. National Management Measures for the Control of Nonpoint Pollution from Agriculture; Washington, DC,2003.

(6) Strokal, M.; Kroeze, C.; Li, L. L.; Luan, S. J.; Wang, H. Z.; Yang, S. S.; Zhang, Y. S. Increasing dissolved nitrogen and phosphorus export by the Pearl River (Zhujiang): a modeling approach at the subbasin scale to assess effective nutrient management. Biogeochemistry 2015, 125 (2), 221-242.

(7) Álvarez-Cabria, M.; Barquín, J.; Peñas, F. J. Modelling the spatial and seasonal variability of water quality for entire river networks:
Relationships with natural and anthropogenic factors. Sci. Total Environ. 2016, 545-546, 152-162.

(8) Lai, G. Y.; Yu, G.; Gui, F. Preliminary study on assessment of nutrient transport in the Taihu Basin based on SWAT modeling. Sci. China, Ser. D: Earth Sci. 2006, 49 (1), 135-145.

(9) Zhang, Q. L.; Chen, Y. X.; Jilani, G.; Shamsi, I. H.; Yu, Q. G. Model AVSWAT apropos of simulating non-point source pollution in Taihu lake basin. J. Hazard. Mater. 2010, 174 (1-3), 824-30.

(10) Qin, B. Q.; Xu, P. Z.; Wu, Q. L.; Luo, L. C.; Zhang, Y. L. Environmental issues of Lake Taihu, China. Hydrobiologia 2007, 581 (1), 3-14.

(11) Zhao, H. X.; Duan, X. J.; Stewart, B.; You, B. S.; Jiang, X. W. Spatial correlations between urbanization and river water pollution in the heavily polluted area of Taihu Lake Basin. China. J. Geogr. Sci. 2013, 23 (4), 735-752.

(12) Zhao, J.; Lin, L. Q.; Yang, K.; Liu, Q. X.; Qian, G. R. Influences of land use on water quality in a reticular river network area: A case study in Shanghai, China. Landscape and Urban Planning 2015, 137, $20-29$.

(13) Stone, R. Ecology. China aims to turn tide against toxic lake pollution. Science 2011, 333 (6047), 1210-1211.

(14) Paerl, H. W.; Hall, N. S.; Calandrino, E. S. Controlling harmful cyanobacterial blooms in a world experiencing anthropogenic and climatic-induced change. Sci. Total Environ. 2011, 409 (10), 17391745.

(15) Peng, T. R.; Lin, H. J.; Wang, C. H.; Liu, T. S.; Kao, S. J. Pollution and variation of stream nitrate in a protected high-mountain watershed of Central Taiwan: evidence from nitrate concentration and nitrogen and oxygen isotope compositions. Environ. Monit. Assess. 2012, 184 (8), 4985-4998.

(16) Ohte, N. Tracing sources and pathways of dissolved nitrate in forest and river ecosystems using high-resolution isotopic techniques: a review. Ecol. Res. 2013, 28 (5), 749-757.

(17) Mengis, M.; Walther, U.; Bernasconi, S. M.; Wehrli, B. Limitations of using $\delta^{18} \mathrm{O}$ for the source identification of nitrate in agricultural soils. Environ. Sci. Technol. 2001, 35 (9), 1840-1844.

(18) Divers, M. T.; Elliott, E. M.; Bain, D. J. Quantification of nitrate sources to an urban stream using dual nitrate isotopes. Environ. Sci. Technol. 2014, 48 (18), 10580-10587.

(19) Koszelnik, P.; Gruca-Rokosz, R. Determination of nitrate isotopic signature in waters of different sources by analysing the nitrogen and oxygen isotopic ratio. Environ. Sci.: Processes Impacts 2013, 15 (4), 751-759.

(20) Thibodeau, B.; Hélie, J. F.; Lehmann, M. F. Variations of the nitrate isotopic composition in the St. Lawrence River caused by seasonal changes in atmospheric nitrogen inputs. Biogeochemistry 2013, 115 (1), 287-298.

(21) Li, S. L.; Liu, C. Q.; Li, J.; Xue, Z. C.; Guan, J.; Lang, Y. C.; Ding, H.; Li, L. B. Evaluation of nitrate source in surface water of southwestern China based on stable isotopes. Environ. Earth Sci. 2013, 68 (1), 219-228.

(22) Yue, F. J.; Li, S. L.; Liu, C. Q.; Zhao, Z. Q.; Hu, J. Using dual isotopes to evaluate sources and transformation of nitrogen in the Liao River, northeast China. Appl. Geochem. 2013, 36 (36), 1-9.

(23) Xue, D. M.; Botte, J.; De Baets, B.; Accoe, F.; Nestler, A.; Taylor, P.; Van Cleemput, O.; Berglund, M.; Boeckx, P. Present limitations and future prospects of stable isotope methods for nitrate source identification in surface- and groundwater. Water Res. 2009, 43 (5), 1159-1170.

(24) Bronders, J.; Tirez, K.; Desmet, N.; Widory, D.; Petelet-Giraud, E.; Bregnot, A.; Boeckx, P. Use of compound-specific nitrogen $(\mathrm{d} 15 \mathrm{~N})$, oxygen $(\mathrm{d} 18 \mathrm{O})$, and bulk boron $(\mathrm{d} 11 \mathrm{~B})$ isotope ratios to identify sources of nitrate-contaminated waters: a guideline to identify polluters. Environ. Forensics 2012, 13 (1), 32-38.

(25) Moore, J. W.; Semmens, B. X. Incorporating uncertainty and prior information into stable isotope mixing models. Ecol. Lett. 2008, 11 (5), 470-480. 
(26) Parnell, A.; Inger, R.; Bearhop, S.; Jackson, A. Source partitioning using stable isotopes: Coping with too much variation. PLoS One 2010, 5 (3), e9672.

(27) Anderson, I. C.; Levine, J. S. Relative rates of nitric oxide and nitrous oxide production by nitrifiers, denitrifiers, and nitrate respirers. Appl. Environ. Microbiol. 1986, 51 (5), 938-945.

(28) Yang, L. P.; Han, J. P.; Xue, J. L.; Zeng, L. Z.; Shi, J. C.; Wu, L. S.; Jiang, Y. H. Nitrate source apportionment in a subtropical watershed using Bayesian model. Sci. Total Environ. 2013, 463-464 (5), 340-347.

(29) Zhang, J. P. Using stable nitrogen and oxygen isotope to identify the distribution and sources of nitrogen in Taige canal, Master thesis; Anhui University of Science and Technology: Huainan, 2015.

(30) Ding, J. T.; Xi, B. D.; Xu, Q. G.; Su, J.; Huo, S. L.; Liu, H. L.; Yu, Y. J.; Zhang, Y. B. Assessment of the sources and transformations of nitrogen in a plain river network region using a stable isotope approach. J. Environ. Sci. 2015, 30 (4), 198-206.

(31) Jin, Z. F.; Pan, Z. Y.; Jin, M. T.; Li, F. L.; Wan, Y.; Gu, B. Determination of nitrate contamination sources using isotopic and chemical indicators in an agricultural region in China. Agric., Ecosyst. Environ. 2012, 155 (155), 78-86.

(32) Minet, E.; Coxon, C. E.; Goodhue, R.; Richards, K. G.; Kalin, R. M.; Meier-Augenstein, W. Evaluating the utility of ${ }^{15} \mathrm{~N}$ and ${ }^{18} \mathrm{O}$ isotope abundance analyses to identify nitrate sources: A soil zone study. Water Res. 2012, 46 (12), 3723-3736.

(33) Kelley, C. J.; Keller, C. K.; Evans, R. D.; Orr, C. H.; Smith, J. L.; Harlow, B. A. Nitrate nitrogen and oxygen isotope ratios for identification of nitrate sources and dominant nitrogen cycle processes in a tile-drained dryland agricultural field. Soil Biol. Biochem. 2013, 57 (3), 731-738.

(34) Yu, L. F.; Zhu, J.; Mulder, J.; Dörsch, P. Multiyear dual nitrate isotope signatures suggest that $\mathrm{N}$-saturated subtropical forested catchments can act as robust N sinks. Global Change Biol. 2016, 22 (11), 3662-3674.

(35) Luo, L. C.; Qin, B. Q.; Yang, L. Y.; Song, Y. Z. Total inputs of phosphorus and nitrogen by wet deposition into Lake Taihu, China. Hydrobiologia 2007, 581 (1), 63-70.

(36) Burns, D. A.; Boyer, E. W.; Elliott, E. M.; Kendall, C. Sources and transformations of nitrate from streams draining varying land uses: Evidence from dual isotope analysis. J. Environ. Qual. 2009, 38 (3), $1149-1159$.

(37) Townsend-Small, A.; McCarthy, M. J.; Brandes, J. A.; Yang, L. Y.; Zhang, L.; Gardner, W. S. Stable isotopic composition of nitrate in Lake Taihu, China, and major inflow rivers. Hydrobiologia 2007, 581 (1), 135-140.

(38) Chen, Z. X.; Yu, L.; Liu, W. G.; Lam, M. H. W.; Liu, G. J.; Yin, $\mathrm{X}$. B. Nitrogen and oxygen isotopic compositions of water-soluble nitrate in Taihu Lake water system, China: implication for nitrate sources and biogeochemical process. Environ. Earth Sci. 2014, 71 (1), 217-223.

(39) Ye, C.; Shen, Z. M.; Zhang, T.; Fan, M. H.; Lei, Y. M.; Zhang, J. D. Long-term joint effect of nutrients and temperature increase on algal growth in Lake Taihu. China. J. Environ. Sci. 2011, 23 (2), 222227.

(40) Paerl, H. W.; Xu, H.; McCarthy, M. J.; Zhu, G. W.; Qin, B. Q.; Li, Y. P.; Gardner, W. S. Controlling harmful cyanobacterial blooms in a hyper-eutrophic lake (Lake Taihu, China): The need for a dual nutrient (N \& P) management strategy. Water Res. 2011, 45 (5), 1973-1983.

(41) Paerl, H. W.; Xu, H.; Hall, N. S. Nutrient limitation dynamics examined on a multi-annual scale in Lake Taihu, China: implications for controlling eutrophication and harmful algal blooms. J. Freshwater Ecol. 2015, 30 (1), 5-24.

(42) Ma, J. R.; Qin, B. Q.; Wu, P.; Zhou, J.; Niu, C.; Deng, J. M. Controlling cyanobacterial blooms by managing nutrient ratio and limitation in a large hyper- eutrophic lake: Lake Taihu, China. J. Environ. Sci. 2015, 27 (1), 80-86.

(43) Finlay, J. C.; Small, G. E.; Sterner, R. W. Human influences on nitrogen removal in lakes. Science 2013, 342 (6155), 247-250.
(44) Bernhardt, E. S. Ecology. Cleaner lakes are dirtier lakes. Science 2013, 342 (6155), 205-206.

(45) Xu, H.; Paerl, H. W.; Qin, B. Q.; Zhu, G. W.; Hall, N. S.; Wu, Y. Determining critical nutrient thresholds needed to control harmful cyanobacterial blooms in Eutrophic Lake Taihu, China. Environ. Sci. Technol. 2015, 49 (2), 1051-1059.

(46) Zhao, Y. Q.; Xia, Y. Q.; Ti, C. P.; Shan, J.; Li, B. L.; Xia, L. L.; Yan, X. Y. Nitrogen removal capacity of the river network in a high nitrogen loading region. Environ. Sci. Technol. 2015, 49 (3), 14271435.

(47) Hu, W. P.; Zhai, S. J.; Zhu, Z. C.; Han, H. J. Impacts of the Yangtze River water transfer on the restoration of Lake Taihu. Ecol. Eng. 2008, 34 (1), 30-49.

(48) Hu, L. M.; Hu, W. P.; Zhai, S. H.; Wu, H. Y. Effects on water quality following water transfer in Lake Taihu, China. Ecol. Eng. 2010, 36 (4), 471-481.

(49) Li, Y. P.; Tang, C. Y.; Wang, C.; Anim, D. O.; Yu, Z. B.; Acharya, K. Improved Yangtze River Diversions: Are they helping to solve algal bloom problems in Lake Taihu, China? Ecol. Eng. 2013, 51 (1), 104116.

(50) Li, Y. P.; Acharya, K.; Yu, Z. B. Modeling impacts of Yangtze River water transfer on water ages in Lake Taihu, China. Ecol. Eng. 2011, 37 (2), 325-334. 